\title{
Titration of $\beta$-Blockers for Patients With Heart Failure
}

\author{
Toshihisa Anzai, MD, PhD
}

B eta-blockers (BBs) are widely used in patients with heart failure (HF), based on several lines of clinical evidence, ${ }^{1-3}$ but the dose of BBs used in clinical practice is still less than the target dose defined in clinical trials. ${ }^{4,5}$ In Japan, this tendency is more apparent than in the USA and Europe. ${ }^{6}$ The reasons suggested for insufficient up-titration of BBs are their short-term adverse hemodynamic effects, such as deterioration of left ventricular (LV) systolic function and lowering of blood pressure and heart rate, and intolerance in patients with advanced age, chronic obstructive pulmonary disease (COPD), chronic kidney disease (CKD), or other coexisting disorders. However, recent clinical findings have shown that $\mathrm{BBs}$ are tolerable even in patients with advanced age ${ }^{7}$ and are also effective in patients with $\mathrm{COPD}^{8}$ or CKD. ${ }^{9}$ According to those findings, up-titration of BBs in patients with HF has become more common in recent years, as is reported by Kato et $\mathrm{al}^{10}$ in this issue of the Journal. They examined 227 consecutive patients hospitalized for $\mathrm{HF}$ with reduced ejection fraction (HFrEF) in whom BBs were introduced on a de novo basis. They show that in recent years (after 2006), the prognosis for patients with $\mathrm{HFrEF}$ significantly improved compared with earlier years (before 2005). This improvement can be explained by an increased BB dose accompanied by lowered resting heart rate. They also demonstrate that lower resting heart rate ( $\leq 71$ beats/min) and higher BB dose ( $\geq 10 \mathrm{mg}$ carvedilol) were significant determinants of better clinical outcomes, suggesting these parameters could be useful surrogate markers when titrating BBs in Japanese patients with HFrEF.

\section{Article p 1001}

Previous clinical studies have shown that the improvement in $\mathrm{EF}$ by $\mathrm{BBs}$ is dose-dependent, suggesting that higher doses of BBs would be better. ${ }^{6,11}$ However, intolerance of BB uptitration is relatively common in the Asian population. In fact, $\beta_{1}$-receptor sensitivity is reported to be higher in Chinese than in Caucasians and African-Americans. ${ }^{12}$ Moreover, it is sometimes difficult to maintain the incentive for up-titrating BBs in asymptomatic HF patients. Therefore, useful surrogate markers for titrating BBs have been anticipated.

It is known that a higher resting heart rate is associated with lower mortality in patients with HF. ${ }^{13-15}$ In a meta-analysis examining the effect of BBs on mortality in terms of heart rate reduction, a $14 \%$ risk reduction was observed with each 5 beats/min decrease in heart rate. ${ }^{16}$ In addition, the improvement in LVEF closely correlated with heart rate reduction. ${ }^{17}$

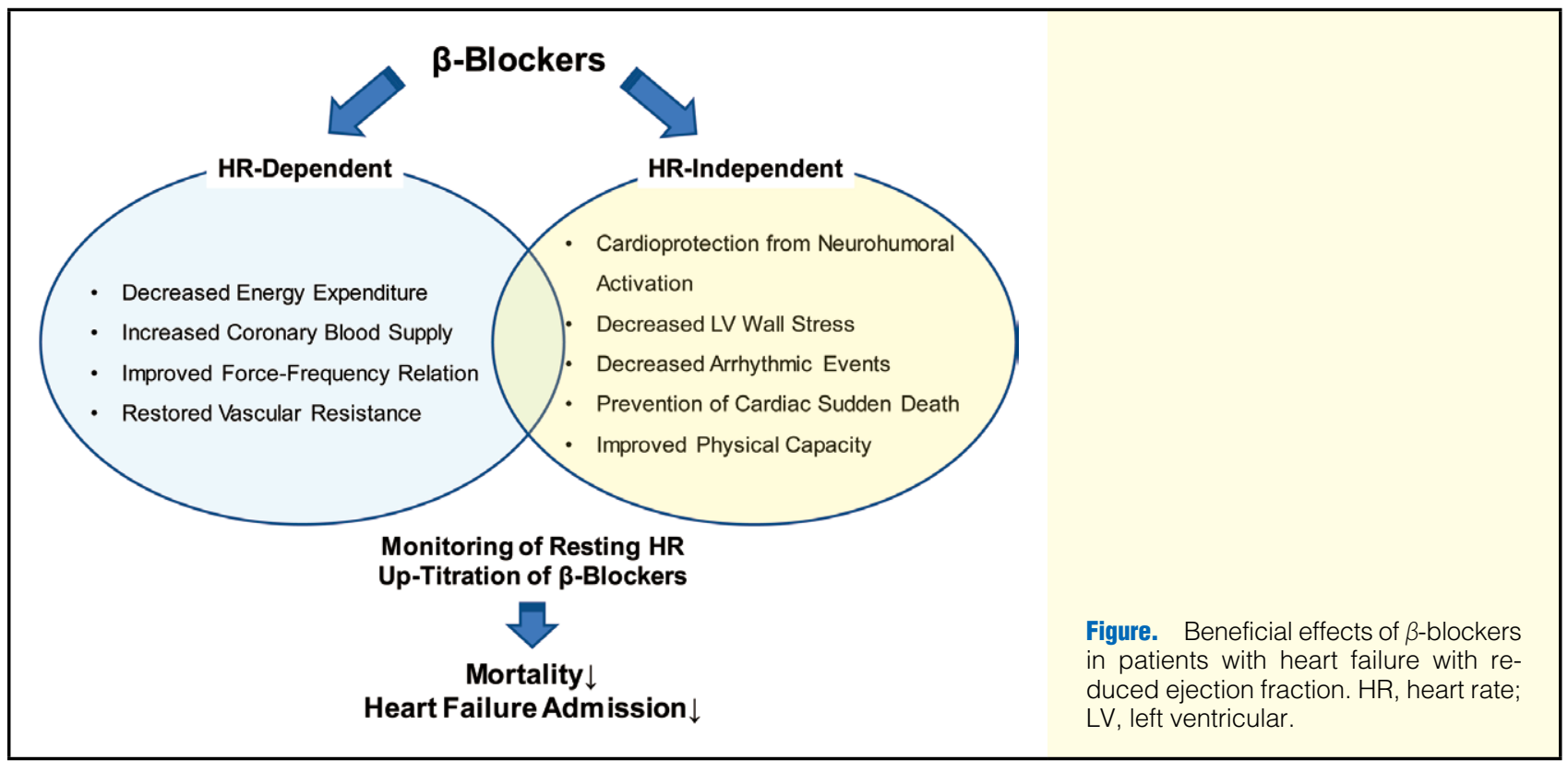

The opinions expressed in this article are not necessarily those of the editors or of the Japanese Circulation Society.

Received January 23, 2013; accepted January 28, 2013; released online February 9, 2013

Department of Cardiovascular Medicine, National Cerebral and Cardiovascular Center, Suita, Japan

Mailing address: Toshihisa Anzai, MD, PhD, Department of Cardiovascular Medicine, National Cerebral and Cardiovascular Center, 5-7-1

Fujishiro-dai, Suita 565-8565, Japan. E-mail: anzai@hsp.ncvc.go.jp

ISSN-1346-9843 doi:10.1253/circj.CJ-13-0123

All rights are reserved to the Japanese Circulation Society. For permissions, please e-mail: cj@j-circ.or.jp 
However, heart rate reduction could be secondary to improved cardiac function and physical capacity by BB treatment. The causative effect of lowering heart rate itself has not been fully elucidated. A recent clinical study using a selective heart rate-lowering drug, an If current inhibitor (ivabradine), showed that heart rate reduction in patients with $\mathrm{HFrEF}$, heart rate $\geq 70$ beats $/ \mathrm{min}$, and sinus rhythm reduced the incidence of cardiovascular death and HF admission, suggesting the importance of heart rate reduction for treatment of HF. ${ }^{18}$ Although the precise mechanisms are still unclear, heart rate reduction possibly exerts its beneficial effects through decreased energy expenditure, increased coronary blood supply by prolonging diastole, improved force-frequency relation and restored vascular resistance. ${ }^{19}$

On the other hand, BB therapy reduces mortality even in patients undergoing cardiac resynchronization therapy with an implantable cardioverter defibrillator whose heart rate is fixed by the artificial pacemaker. ${ }^{20}$ Because BB therapy has several beneficial effects, including reduction in myocardial ischemia, arrhythmias and LV wall stress and cardioprotection from neurohumoral activation, heart rate reduction is not the sole mechanism of the survival benefit of BBs (Figure).

The major clinical benefit of BBs is preventing sudden cardiac death (SCD). Because sympathetic activation plays a major role in the development of SCD, heart rate reduction is not necessarily required for SCD prevention. In fact, the SHIFT trial showed that ivabradine significantly reduced the risk of $\mathrm{HF}$ admission and death from HF, but not the risk of all cardiovascular death including SCD. ${ }^{18}$ Kato et al demonstrate that the $\mathrm{BB}$ dose, but not heart rate reduction, was an independent determinant of the composite endpoint of hospitalization for worsening $\mathrm{HF}$ and/or all-cause death by multivariate analysis. ${ }^{10}$ In contrast, the previous meta-analysis showed that the magnitude of heart rate reduction was statistically significantly associated with a decreased risk ratio of all-cause mortality by $\mathrm{BBs}$ in $\mathrm{HF}$, whereas the dose of BB was not. ${ }^{16}$ However, the average dose in the meta-analysis was higher than that of the present study in Japan. Although the subanalysis of CIBIS II demonstrated that bisoprolol reduced mortality in HF patients at all tolerated dose levels and its withdrawal increased the risk of mortality, all-cause mortality was significantly reduced in the moderate dose (bisoprolol 5 or $7.5 \mathrm{mg} /$ day) and high dose (bisoprolol $10 \mathrm{mg} /$ day) groups compared with the low dose group (bisoprolol $\leq 3.75 \mathrm{mg} /$ day). Because a dose of carvedilol $<10 \mathrm{mg}$ is lower than the so-called "low dose" in Western countries, careful titration up to at least $10 \mathrm{mg}$ carvedilol would be recommended to obtain survival benefit in Japanese patients with HFrEF.

Resting heart rate is a practical surrogate marker to titrate BBs. However, heart rate at peak exercise and 24-h average heart rate are also important to assess the degree of $\beta$-blockade. Further investigations will be required to establish a protocol to titrate BBs in individual patients with HF.

\section{References}

1. Foody JM, Farrell MH, Krumholz HM. Beta-blocker therapy in heart failure: Scientific review. JAMA 2002; 287: 883-889.

2. Kubon C, Mistry NB, Grundvold I, Halvorsen S, Kjeldsen SE, Westheim AS. The role of beta-blockers in the treatment of chronic heart failure. Trends Pharmacol Sci 2011; 32: 206-212.
3. Nair AP, Timoh T, Fuster V. Contemporary medical management of systolic heart failure. Circ J 2012; 76: 268-277.

4. Gattis WA, O'Connor CM, Gallup DS, Hasselblad V, Gheorghiade M. Predischarge initiation of carvedilol in patients hospitalized for decompensated heart failure: results of the Initiation Management Predischarge: Process for Assessment of Carvedilol Therapy in Heart Failure (IMPACT-HF) trial. J Am Coll Cardiol 2004; 43: 1534-1541.

5. Fonarow GC, Abraham WT, Albert NM, Stough WG, Gheorghiade M, Greenberg BH, et al. Dosing of beta-blocker therapy before, during, and after hospitalization for heart failure (from Organized Program to Initiate Lifesaving Treatment in Hospitalized Patients with Heart Failure). Am J Cardiol 2008; 102: 1524-1529.

6. Hori M, Sasayama S, Kitabatake A, Toyo-oka T, Handa S, Yokoyama $\mathrm{M}$, et al. Low-dose carvedilol improves left ventricular function and reduces cardiovascular hospitalization in Japanese patients with chronic heart failure: The Multicenter Carvedilol Heart Failure Dose Assessment (MUCHA) trial. Am Heart J 2004; 147: 324-330.

7. Dungen HD, Apostolovic S, Inkrot S, Tahirovic E, Topper A, Mehrhof $\mathrm{F}$, et al. Titration to target dose of bisoprolol vs. carvedilol in elderly patients with heart failure: The CIBIS-ELD trial. Eur J Heart Fail 2011; 13: 670-680.

8. Hawkins NM, Huang Z, Pieper KS, Solomon SD, Kober L, Velazquez EJ, et al. Chronic obstructive pulmonary disease is an independent predictor of death but not atherosclerotic events in patients with myocardial infarction: Analysis of the Valsartan in Acute Myocardial Infarction Trial (VALIANT). Eur J Heart Fail 2009; 11: 292 298.

9. Badve SV, Roberts MA, Hawley CM, Cass A, Garg AX, Krum H, et al. Effects of beta-adrenergic antagonists in patients with chronic kidney disease: A systematic review and meta-analysis. $\mathrm{J} \mathrm{Am} \mathrm{Coll}$ Cardiol 2011; 58: 1152-1161.

10. Kato N, Kinugawa K, Imamura T, Muraoka H, Minatsuki S, Inaba T, et al. Trend of clinical outcome and surrogate markers during titration of $\beta$-blocker in heart failure patients with reduced ejection fraction: Relevance of achieved heart rate and $\beta$-blocker dose. Circ J 2013; 77: $1001-1008$.

11. Bristow MR, Gilbert EM, Abraham WT, Adams KF, Fowler MB, Hershberger RE, et al. Carvedilol produces dose-related improvements in left ventricular function and survival in subjects with chronic heart failure: MOCHA Investigators. Circulation 1996; 94: 2807-2816.

12. Xie HG, Kim RB, Wood AJ, Stein CM. Molecular basis of ethnic differences in drug disposition and response. Annu Rev Pharmacol Toxicol 2001; 41: 815-850.

13. Aaronson KD, Schwartz JS, Chen TM, Wong KL, Goin JE, Mancini DM. Development and prospective validation of a clinical index to predict survival in ambulatory patients referred for cardiac transplant evaluation. Circulation 1997; 95: 2660-2667.

14. Fosbol EL, Seibaek M, Brendorp B, Moller DV, Thune JJ, Gislason $\mathrm{GH}$, et al. Long-term prognostic importance of resting heart rate in patients with left ventricular dysfunction in connection with either heart failure or myocardial infarction: The DIAMOND study. Int $J$ Cardiol 2010; 140: 279-286.

15. Heusch G. Heart rate and heart failure: Not a simple relationship. Circ J 2011; 75: 229-236.

16. McAlister FA, Wiebe N, Ezekowitz JA, Leung AA, Armstrong PW. Meta-analysis: Beta-blocker dose, heart rate reduction, and death in patients with heart failure. Ann Intern Med 2009; 150: 784-794.

17. Doughty RN, Whalley GA, Walsh HA, Gamble GD, Lopez-Sendon J, Sharpe N. Effects of carvedilol on left ventricular remodeling after acute myocardial infarction: The CAPRICORN Echo Substudy. Circulation 2004; 109: 201-206.

18. Swedberg K, Komajda M, Bohm M, Borer JS, Ford I, Dubost-Brama $\mathrm{A}$, et al. Ivabradine and outcomes in chronic heart failure (SHIFT): A randomised placebo-controlled study. Lancet 2010; 376: 875-885.

19. Bohm M, Swedberg K, Komajda M, Borer JS, Ford I, Dubost-Brama A, et al. Heart rate as a risk factor in chronic heart failure (SHIFT): The association between heart rate and outcomes in a randomised placebo-controlled trial. Lancet 2010; 376: 886-894.

20. Kreuz J, Horlbeck F, Linhart M, Mellert F, Fimmers R, Schrickel J, et al. Independent predictors of mortality in patients with advanced heart failure treated by cardiac resynchronization therapy. Europace 2012; 14: 1596-1601. 